\title{
Dios se suicidó. \\ Invitación al exterminio humano en la visión transpersonal de Mainländer
}

\author{
God killed himself. \\ Invitation to human extermination in the transpersonal vision of \\ Mainländer
}

Héctor Sevilla Godinez*

\begin{abstract}
Resumen: El presente artículo aborda algunos de los aspectos centrales de la filosofía propuesta por Philip Mainländer. La intención se enfoca en vislumbrar las implicaciones que suscita el pensamiento de este autor, principalmente en lo tocante a la actitud que se deriva de la contemplación del exterminio de lo humano como una solución consecuente al suicidio y muerte de Dios. Se analiza la intención del hombre en el mundo desde tal perspectiva y se ofrecen vínculos con autores que han acogido para sí los escabrosas y complejos senderos del nihilismo comprometido. El texto termina con una serie de alternativas de redención de lo humano a través de una filosofía sobre la muerte y no en función de la muerte misma.
\end{abstract}

Palabras clave: Exterminio, Muerte de Dios, Redención, Suicidio, Nihilismo

Abstract: This article addresses some of the central aspects of the philosophy proposed by Philip Mainländer. The intention is focused on glimpsing the implications of this author's thinking, mainly with regard to the attitude derived from the contemplation of the extermination of the human as a consequent solution to the suicide and death of God. The intention of man in the world is analyzed from this

\footnotetext{
* Doctor en Filosofía y en Ciencias del Desarrollo Humano. Miembro de la Asociación Filosófica de México y miembro fundador de la Asociación Transpersonal Iberoamericana. Forma parte del Sistema Nacional de Investigadores del CONACYT (Nivel 1) en México. Es profesor e investigador en la Universidad de Guadalajara. Entre sus obras destacan los ensayos filosóficos Contemplar la Nada (2018), Espiritualidad Filosófica (2018) y Apología del vacio (2016). Ha publicado más de setenta artículos, en los cuales se destacan sus líneas de investigación centrales: el nihilismo, la mística y la metafísica. Dirección electrónica: hectorsevilla@hotmail.com
} 
perspective and links are offered with authors who have welcomed the rugged and complex paths of compromised nihilism. The text ends with a series of alternatives for the redemption of the human through a philosophy about death and not as a function of death itself.

Key Words: Extermination, Death of God, Redemption, Suicide, Nihilism

Sobre las negras flores de la muerte flota mi espíritu, como la abeja sobre las flores primaverales; y ninguna le niega el dulce veneno de su cáliz. ${ }^{1}$

\section{Exordio}

En este artículo se abordan algunos de los aspectos centrales de la filosofía propuesta por Philipp Mainländer. La intención se enfocará en vislumbrar las implicaciones que suscita el pensamiento de este autor, principalmente en lo tocante a la actitud que se deriva de la contemplación del exterminio de lo humano como una solución consecuente al suicidio y muerte de Dios. Se analizará la intención del hombre en el mundo desde tal perspectiva y se ofrecerán vínculos con otros autores que han acogido para sí los escabrosos y complejos senderos del nihilismo comprometido. En ánimo conciliador, el texto termina con una serie de alternativas de redención de lo humano a través de una filosofía sobre la muerte y no en función de la muerte misma.

\section{El camino hacia el exterminio}

Tener los pies puestos sobre la tierra nos implica comprobar, si la visión no ha sido cegada por empalagosas compensaciones, que "la historia de una vida es siempre la historia de un sufrimiento". ${ }^{2}$ Es a partir de ahí, de un sufrimiento ineludible y certero, desde donde se construyen las edificaciones

\footnotetext{
${ }^{1}$ Mainländer, Philipp, Diario de un poeta, Madrid, Plaza y Valdés, 2015, p. 151.

${ }^{2}$ Nietzsche, Friedrich, Ecce Homo, Ciudad de México, Grupo Editorial Tomo, 2005, p. 127.
} 
personales más íntimas y duraderas. Cioran, por ejemplo, cuando advirtió su propio camino de vida, escribió la siguiente sentencia: "Lo mejor que yo poseo en mí, y también lo que he perdido, se lo debo al sufrimiento". 3 Desde ese punto de vista forjado en el reconocimiento de la tragedia que supone la vida, es de donde partió Philipp Batz para proponer su reflexión filosófica.

Nacido en 1841, Philipp creció en la ciudad de Offenbach, la cual está situada a orillas del río Main; es por tal motivo que recibió el seudónimo Mainländer, el cual hace referencia a la "región del Main". Motivado por su lectura de Leopardi y posteriormente de Schopenhauer, "Mainländer se apartaba del mundo para cultivar su erudición". ${ }^{4}$ En ese aislamiento creativo fue capaz de persuadirse de que "la miseria que llena este mundo protesta a gritos contra la hipótesis de una obra perfecta debida a un ser infinitamente sabio, bueno y poderoso". ${ }^{5}$ En el filósofo del Main no cesó la conciencia de que debía existir una manera de explicar el origen del universo en forma distinta a la tradicional; por tal motivo, trasladó a la filosofía su interés personal y poético, volviéndose cada vez más consciente de la importancia de encontrar respuestas. La locura por explicar el origen de lo existente, así como sus consecuencias en la vida humana lo atrajo a tal grado que constituyó su motivación esencial. En ese sentido, es fácil comprobar con Mainländer que "toda existencia que carezca de una gran locura carece de valor". ${ }^{6}$

De acuerdo con Mainländer, "la filosofía de la redención fundamenta el ateísmo no en una creencia cualquiera, sino como filosofía en el saber, y por esta razón queda el ateísmo por primera vez fundamentado de un modo científico".7 A pesar de la evidente disputa que podría hacerse respecto al uso del término "científico" en la aseveración anterior, está claro que el interés de Mainländer se situó en encontrar una explicación que no estuviese necesariamente centrada en un credo exclusivo. Su aportación, tal como afirma Volpi, fue decisiva para la construcción del pensamiento filosófico de

${ }^{3}$ Cioran, Emil, En las cimas de la desesperación, Ciudad de México, Tusquets, 2009, p. 126.

${ }^{4}$ Baquedano, Sandra, "El pesimismo entrópico en las cosmologías filosóficas de la voluntad", en Mainländer, Philipp, Filosofía de la redención. Antología, Santiago, FCE, 2013, p. 14.

${ }^{5}$ Schopenhauer, Arthur, El amor, las mujeres y la muerte, Madrid, EDAF, p. 123.

${ }^{6}$ Cioran, E., En las cimas de la desesperación, p. 24.

${ }^{7}$ Mainländer, P., Filosofía de la redención. Antología, p. 46. 
Nietzsche, cuya maduración intelectual fue obtenida no sólo a partir de la lectura de Schopenhauer, Hartmann o Bahnsen, sino también de Mainländer. ${ }^{8}$ Igualmente, la influencia del filósofo del Main es observable en las obras de Jorge Luis Borges y Emile Cioran. ${ }^{9}$ Su obra principal, Die Philosophie der Erlösung, publicada en 1876, ha sido comúnmente olvidada por la academia hispanoparlante hasta estos días, de no ser por una serie de traducciones ${ }^{10}$ que intentan reavivarla.

El camino a la apología del exterminio humano, contenida en la Filosofía de la Redención de Mainländer, brilla con independencia de la repulsión que a muchos causa su propuesta. La filosofía redentora que se encuentra en sus páginas, sin importar que se concuerde o no con quien la refiere, encumbra la obra de Mainländer a partir de su marcada diferencia con tantas alternativas dulzonas, acomodaticias y convenientes, que pululan en el mundo académico y que reiteran tradiciones que no involucran el compromiso intelectual de los sumisos seguidores; por el contrario, en Mainländer se encuentra un testimonio que lleva a la filosofía hasta sus últimas consecuencias mediante una suerte de arte que combina la reflexión y lo poético. Al filósofo que se precie de serlo se le debe confrontar con su propia elaboración y, si tiene suerte, podrá distinguirse de la medianía, pues "los filósofos, en medida en que son distinguibles, se sitúan entre los artistas y los científicos". ${ }^{11}$ Mainländer fue, sin duda, un escéptico hacia las explicaciones cotidianas sobre la divinidad y el origen del universo, dudó de la libertad y de la posibilidad de un sentido a partir de las valoraciones incipientes de su contexto. Es difícil afirmar que Nietzsche pensaba en él cuando afirmó que "los escépticos son el único tipo respetable entre el pueblo de los filósofos", ${ }^{12}$ pero, al menos, puede asumirse que entre tal grupo se encuentra Mainländer.

\footnotetext{
${ }^{8}$ Cfr. Volpi, Franco, El nibilismo, Buenos Aires, Biblos, 2005, p. 47.

${ }^{9}$ Ibidem, p. 52.

${ }^{10}$ En el presente artículo se utilizó la traducción procedente de la antología realizada por Sandra Baquedano (Santiago, FCE, 2007), quien seleccionó y editó algunos pasajes de la máxima obra de Mainländer. Asimismo, existe una encomiable traducción completa de Die Philosophie der Erlösung, realizada por Manuel Pérez Cornejo y editada por Carlos Javier González (Madrid, Ediciones Xorki, 2014).

${ }^{11}$ Scharfstein, Ben-Ami, Los filósofos y sus vidas, Madrid, Cátedra, p. 94.

${ }^{12}$ Nietzsche, F., Ecce homo, p. 40.
} 
No pretendo pasar por alto que, tal como sucede con la mayoría de los filósofos propositivos, la obra de Mainländer es una respuesta a las circunstancias de su vida, pues no olvidemos que "la filosofía es el arte de disimular los tormentos y los suplicios propios". ${ }^{13}$ Tal cuestión, sin menoscabo de la calidad o lucidez del pensamiento del autor del que se trate, no hace más que afirmar el valor de una subjetividad apremiada por las trágicas situaciones ordinarias que le acontecen. Tres de los seis hermanos de Mainländer eligieron el suicidio, uno de los cuales, incluso, lo culpó injustamente por su decisión. La madre y la abuela del filósofo de la redención fueron recordadas como mujeres de profundas nostalgias y oscuras visiones; de ambas aceptó Mainländer haber heredado sus características. En 1865 quedó terriblemente afectado al encontrar muerta a su madre tras regresar de un paseo a orillas del Rin, ${ }^{14}$ y al siguiente año eligió sacrificarse en el campo de batalla defendiendo la unificación de Alemania, pero no logró hacerse soldado debido a su precaria salud; sin embargo, su sacrificio fue consumado más adelante, en otras circunstancias y para otro fin.

\section{El nihilismo y la muerte de Dios}

Arkadij, el personaje de la novela Padres e Hijos de Turguéniev, afirma que "el nihilista es un hombre que no se inclina ante ninguna autoridad, que no da fe a ningún principio, cualquiera sea el respeto de que tal principio esté rodeado". ${ }^{15}$ La noción de nihilismo que propone Turguéniev ha sido motivo de otros estudios, ${ }^{16}$ puesto que usualmente es considerada, al menos en el terreno literario, uno de los pronunciamientos nihilistas con mayor impacto en la sociedad rusa. Con tal apreciación es coincidente la afirmación que Nietzsche realiza sobre la muerte de Dios, en el entendido de que no considera posible una autoridad mayor al hombre. La afirmación sobre la muerte de Dios ha sido

\footnotetext{
${ }^{13}$ Cioran, E., En las cimas de la desesperación, p. 52.

${ }^{14}$ Cfr. Baquedano, S., "El pesimismo entrópico en las cosmologías filosóficas de la voluntad", p. 13.

15 Turguéniev, Iván, Padres e Hijos, Madrid, Alianza Editorial, 1972, p. 23.

16 Cfr. Gil, Marta, "La noción de Nihilismo en Padres e Hijos de Iván Turguéniev", Cartaphilus, 9, 2011, pp. 49-60.
} 
atribuida al filósofo que propuso la idea de superhombre (Übermensch), lo cual es comprobable si revisamos las secciones 108, 125 y 343 de su Gaya Ciencia o consultamos Así habló Zaratustra, obra en la cual no sólo se afirma que "Dios ha muerto", ${ }^{17}$ sino que "muertos están todos los dioses: ahora queremos que viva el superhombre". ${ }^{18}$ No obstante, la sentencia había sido anteriormente utilizada por Hegel en su Fenomenología del Espíritu cuando explica la conciencia desventurada comparándola con "el dolor que se expresa en las duras palabras de que Dios ha muerto". ${ }^{19}$ Evidentemente, en las afirmaciones que realiza Nietzsche existe un eco de la sentencia hegeliana y, desde luego, no intenta significar que una entidad omnipotente ha dejado de vivir, sino que, por el contrario, son los hombres los que han de matar la idea de Dios para poder vivir por sí mismos.

Más allá de la coincidencia entre Mainländer y Nietzsche en lo tocante a la afirmación de la muerte de Dios, es en el primero en el que sí se connota el fin sustancial de la existencia de una entidad divina. Para el filósofo que nos ocupa, quien mató a Dios no fue el hombre, sino Dios mismo en el impulso evidente de su transitar hacia la nada. De tal modo, distinto al anuncio de la muerte de Dios, la propuesta de Mainländer advierte un suicidio divino. En ese sentido, "la definición correcta de libertad es, por consiguiente, sólo aplicable a Dios antes del universo". ${ }^{20}$ Ahora bien, es posible deducir que la afirmación realizada por Nietzsche no está sustentada en la creencia de la existencia de Dios, sin importar si tal hubiese sido previa o posterior a la muerte. Es notoria esta postura cuando advierte lúdicamente su desazón con otro autor: " $¿ A c a s o$ yo mismo estoy un poco envidioso de Stendhal? Me quitó el mejor chiste ateísta, un chiste que precisamente yo habría podido hacer: la única disculpa de Dios es que no existe". ${ }^{21}$ Siguiendo estos argumentos, se deduce que la autoridad divina es negada por el filósofo evocador de Zaratustra, por lo que el término de nihilista, al menos el referido por Turguéniev, aplica consecuentemente con él. Sin embargo, en lo referente a Mainländer, en el entendido de que no niega la existencia divina previa a la creación del universo,

\footnotetext{
${ }^{17}$ Nietzsche, Friedrich, Así habló Zaratustra, Madrid, Alianza Editorial, 2012, p. 46.

${ }^{18} \mathrm{Ibidem}$, p. 146.

${ }^{19}$ Hegel, Friedrich, Fenomenología del Espiritu, Ciudad de México, FCE, 2012, p. 435.

${ }^{20}$ Mainländer, P., Filosofía de la redención, p. 121.

${ }^{21}$ Nietzsche, F., Ecce Homo, p. 42.
} 
la afirmación de su nihilismo no es acorde con lo enunciado por el novelista ruso.

La existencia antecedente de Dios es fundamental en la filosofía de Mainländer y en ella se sustenta la entropía del universo en su transitar a la Nada. Dios debió morir para que el resto de entidades existentes pudiese vivir. En ese sentido, "Dios (...), esta unidad simple que ha sido, ya no existe más. Ella se ha fragmentado, transformándose su esencia absoluta en el universo de la multiplicidad. Dios ha muerto y su muerte fue la vida del universo". ${ }^{22}$ De tal modo, la creación del universo fue, efectivamente, obra de Dios, pero no en función de una voluntad por la vida, sino por la muerte, su propia muerte, de la cual es heredero el hombre viviente, al menos hasta que es congruente con el designio implícito en su naturaleza.

En Mainländer se encuentra una afirmación distinta a la que Nietzsche enunció en función de la necesidad de negar la idea de Dios y erradicar la sumisión de los valores a una abstracción absoluta. Para el filósofo del Main, Dios fue el único ser verdaderamente libre puesto que fue capaz de elegir su muerte. Bajo esa lógica transpersonal se entiende que "a Dios le quedó sólo una acción posible y ciertamente fue libre, dado que él no estaba bajo ningún tipo de coacción, pues del mismo modo en que bien pudo prescindir de ésta, pudo ejecutarla, es decir, entrar en la absoluta nada, en el nibil negativum, a saber: exterminarse completamente, dejar de existir". ${ }^{23}$

De esta manera, el exterminio humano se encuentra en consonancia necesaria e irrenunciable con el exterminio que Dios practicó sobre sí mismo. La postura de Mainländer se separa de la muerte de Dios expresada en el nihilismo nietzscheano al considerar que la redención de la vida es más una consecuencia necesaria del suicidio de Dios y menos una liberación vital sustentada en el asesinato de las ideas sobre lo divino. Por lo tanto, el término de "exterminio" podría asociarse con un abismo, pero no es una catástrofe, sino que es evidencia de la ejecución que el hombre realiza por derivación de su semejanza con Dios en cuanto que lo humano es creación derivada del suicidio del primer y único ser libre.

22 Mainländer, Filosofía de la redención, p. 49.

23 Ibidem, p. 54. 
Precisamente, para Mainländer, la omnipotencia de Dios abarca también la posibilidad de su autodestrucción, de su entrega a la nada absoluta. En tal óptica, las predicaciones tradicionales subyacen en el equívoco. El deseo de Dios hacia su no-ser es el principio de toda la filosofía. Es por ello que Mainländer advierte: "Los teólogos de todos los tiempos le han otorgado a Dios, irreflexivamente, el predicado de omnipotencia, es decir, le atribuyeron el poder de ejecutar todo lo que quiso. Al hacerlo, ninguno de ellos pensó en la posibilidad de que Dios también pudiera querer devenir él mismo una nada". 24

A favor de tal argumento se asevera también que "en el campo únicamente inmanente, resultará convincente para cualquiera que el cosmos se mueve efectivamente del ser al no ser". ${ }^{25}$ El Big Bang, entendido como el momento de inicio del universo tal como lo conocemos, es el instante en que Dios se dispersa y se derivan de Él las partículas de todo lo existente, es decir, aquello en lo que Dios se convirtió. Sin embargo, debido a que "Dios quiso el no ser", 26 todo lo que procede de Él deberá, por tal motivo, dirigirse a su destrucción, su exterminio inevitable. Por ende, reproducirse por mediación de los hijos es contraponer y contradecir el fin más íntimo del universo, a saber, destruirse a sí mismo. Tener vástagos bajo esta versión equivale a tergiversar la elección divina. Dios, como esencia máxima, se ha multiplicado a partir de su desintegración, generando con ello que los individuos contengan el afán de no ser. Esto explica que compitan entre sí, debilitándose mutuamente. A la vez, la suma de estos debilitamientos coincide con la meta del no-ser que contiene el universo. Por ende, "cada individuo será llevado a través del debilitamiento de su fuerza, en su proceso evolutivo, hasta el punto en que su afán de alcanzar el exterminio pueda cumplirse". ${ }^{27}$ Es comprensible que, desde esta perspectiva, la virginidad sea vista como algo saludable porque es exigible para no tener hijos, pues "aquellos que ya perviven en los hijos (...) han desperdiciado la posibilidad de la redención en esta generación". ${ }^{28}$

\footnotetext{
${ }^{24}$ Ibidem, p. 55.

25 Ibidem, p. 56.

${ }^{26}$ Ibidem, p. 57.

27 Ibidem.

${ }^{28}$ Ibidem, p. 135.
} 
Con todo esto puede observarse, tal como afirmó Scharfstein, que "todo filósofo digno de tal nombre crea un tipo de ideas. Este modelo ha de ser, al menos en parte, la verdad que él está buscando". ${ }^{29}$ Si bien el suicidio del hombre termina con todo lo que el hombre es, en el caso de Dios su suicidio lo inicia todo. En algunas aristas de esta reflexión coincide Cioran cuando estipula que "es característico de las personas normales considerar la muerte como algo que procede del exterior, y no como una fatalidad inherente al ser". 30 De tal manera, si la fatalidad es algo irrenunciable por estar en la esencia de todo lo que existe, "¿por qué no admitir un triunfo final del no-ser, por qué no admitir que la existencia se dirige hacia la nada, y el ser hacia el no-ser?". ${ }^{31}$ Es evidente que los planteamientos derivados del pensamiento de Mainländer no conducen a la veta de un protagonismo en el hombre, sino que su visión de lo transpersonal produjo en él la convicción de que, sin importar cuál sea nuestra voluntad, todo ha sido escrito antes de nuestro nacimiento en función de un suicidio que devino en causa de lo existente.

\section{El suicidio que lo inicia todo}

Tal como afirma Camus, "no hay sino un problema filosófico realmente serio: el suicidio". ${ }^{32}$ Y si del suicidio del que se trata es el de Dios, la encrucijada toma proporciones épicas. Pensar en ello, creerlo, vuelve al osado pensador en un ente que ya no puede mirar las cosas de la misma manera, pues "un hombre es siempre presa de sus verdades". ${ }^{33}$

Según Mainländer, la intención de Dios en el momento supremo de su libertad, cuando elige dejar de ser, fue volver a la Nada. En esto, el filósofo de la redención concuerda con Leopardi, quien aseguraba en el Zibaldone que "el principio de las cosas, y de Dios mismo, es la nada". ${ }^{44}$ La suerte de un Dios que no se hubiese suicidado no sería alentadora si se toman en cuenta las

\footnotetext{
${ }^{29}$ Scharfstein, B., Los filósofos y sus vidas, p. 90.

${ }^{30}$ Cioran, E., En las cimas de la desesperación, p. 44.

31 Ibidem, p. 92.

${ }^{32}$ Camus, Albert, El mito de Sísifo, Buenos Aires, Alianza Editorial, 2006, p. 13.

${ }^{33}$ Cioran, E., En las cimas de la desesperación, p. 47.

${ }^{34}$ Leopardi, Giacomo, Zibaldone, Milán, Mondadori, I, p. 971.
} 
palabras siguientes de Schopenhauer: "Si Dios ha hecho este mundo, yo no quisiera ser Dios. La miseria del mundo me desgarraría el corazón". ${ }^{35} \mathrm{El}$ hombre, que sí está en este mundo, no puede cegarse ante las evidencias que observa frente a sí, constantemente encuentra motivos para comprobar que "conspira todo en el universo y en el individuo para el no ser". ${ }^{36}$ Para muchos, estar en el mundo es motivo suficiente para intentar ser mejores personas, sin importar que Dios se haya suicidado o no; incluso, sin que sea significativo que Él esté o no presente, a muchos les parece suficiente con poseer el estandarte de la condición humana y afirman que eso basta para resolver sus dudas y regocijarse tranquilamente en tal prodigio, como si el hecho de ser un humano atrajera por sí mismo el sentido a la existencia. Evidentemente, "nada más comprensible que quienes apenas han superado el estado animal o vegetal aspiren a la condición de seres humanos. Pero quienes saben lo que ella significa intentan convertirse en todo menos en eso". ${ }^{37}$ Tal fue el caso de Mainländer, quien, según Volpi, "avanza una osada hipótesis teológicometafísica: la voluntad de muerte que es inherente a todo el ser depende del hecho de que la sustancia divina (...) transita de su originaria unidad trascendente a la pluralidad inmanente del mundo, el cual, en esta transición, recibe su propia génesis". 38

La sensatez conlleva, según Mainländer, a ser congruentes con las circunstancias desde las cuales se ha originado el mundo. El suicidio de Dios lo ha iniciado todo, su martirio voluntario produjo una derivación involuntaria: la creación. Es por esto que el filósofo del Main afirma que "sólo una gran ley dominó la naturaleza desde el principio, la misma que la domina y la dominará hasta su aniquilación total: la ley del debilitamiento de la fuerza". ${ }^{39}$ En ello coincide Cioran cuando deduce que "si la existencia individual es de una atracción tan brutal se debe a que nació de un desequilibrio, de una desigualdad del fondo original de la vida". ${ }^{40} \mathrm{Y}$ todo converge hacia un final común: la nada. Mainländer la reconoce como una causa final, la única que puede admitir el

\footnotetext{
35 Schopenhauer, A., El amor, las mujeres y la muerte, p. 139.

36 Mainländer, P., Filosofía de la redención, p. 66.

${ }^{37}$ Cioran, E., En las cimas de la desesperación, p. 119.

${ }^{38}$ Volpi, F., El nihilismo, p. 49.

${ }^{39}$ Mainländer, P., Filosofía de la redención, p. 63.

${ }^{40}$ Cioran, Emil, Breviario de los vencidos, Ciudad de México, Tusquets, 2010, p. 31.
} 
filósofo inmanente, ${ }^{41}$ aunque tal reconocimiento sea sólo de forma regulativa. Podría conjeturarse que la filosofía de la redención es una oportuna salida ideada por el pensador del Main para escaparse del tormento de vivir y justificar su liberación de semejante cárcel. En caso de que así hubiese sido (lo cual no importa objetar ahora), se igualaría la intención de Mainländer con aquella que mantienen grandes multitudes que anhelan crear un modo más conveniente de entender el orden de las cosas. Finalmente, tal como cuestiona Nietzsche en El Anticristo: "¿Quién es el único que tiene motivos para salirse de la realidad por medio de una mentira? Aquél a quien la realidad hace padecer". ${ }^{42}$

A pesar de que Nietzsche llegó a afirmar que "Schopenhauer se equivocó en todo", ${ }^{43}$ es posible encontrar varias coincidencias entre ellos. Una de las fundamentales apunta a que el optimismo, con toda su suerte de salidas y respuestas simples a los problemas filosóficos, no es una redención por sí misma, sino una falsificación. En palabras de Schopenhauer:

El optimismo (...) no sólo es una doctrina falsa; es una doctrina corruptora, porque nos presenta la vida como un estado apetecible y da como objetivo de la vida la felicidad del hombre. Desde ese momento, cada cual se imagina que tiene los más justificados derechos a la felicidad y al goce. Así, pues, si, como es harto frecuente, no le tocan en suerte esos bienes, se cree víctima de una injusticia. ${ }^{44}$

Coincidentemente con Mainländer, puede afirmarse que tal optimismo es una salida falsa y pueril. Por el contrario, la vida consiste solamente en un morir que no se interrumpe. Es comprensible que semejante aseveración no sea aceptada categóricamente en forma general sin oponer algunas resistencias, pues "no se puede negar que la representación de un Dios Padre personal y cariñoso conmueva más al corazón humano (...) y despierte un anhelo más

\footnotetext{
${ }^{41}$ Cfr. Mainländer, P., Filosofía de la redención, p. 65.

${ }^{42}$ Nietzsche, Friedrich, El Anticristo, Ciudad de México, Editores Mexicanos Unidos, 1998 , p. 30.

43 Nietzsche, F., Ecce Homo, p. 74.

44 Schopenhauer, A., El amor, las mujeres y la muerte, p. 178.
} 
ardiente que la nada absoluta". ${ }^{45}$ Sin embargo, "de la misma manera en que la muerte es inconcebible sin la nada, la vida es inconcebible sin un principio de negatividad". ${ }^{46}$ Este principio negativo termina siendo liberador y redentor en amplio sentido, sobre todo si consideramos que "la vida es el infierno, y [que] la dulce y plácida noche de la muerte absoluta es la aniquilación del infierno". ${ }^{47}$ Así, una vez redimidos, "la inmanencia de la muerte revela el triunfo definitivo de la nada sobre la vida, probando así que la muerte existe únicamente para actualizar progresivamente el camino hacia la nada". ${ }^{48}$

Por todo esto, procrear hijos sería como un volver a nacer, es decir, "tener que seguir sin tregua ni paz el camino de las espinosas y pedregosas vías de la existencia en los hijos infelices", ${ }^{49}$ lo cual es, sin duda, un pensamiento espantoso y desesperante. ${ }^{50}$ Por derivación se entenderá que si Dios se ha suicidado, tal como Mainländer sustentaba, la existencia de los otrora llamados "sus hijos" no ha sido por su voluntad, sino por una inevitable derivación de su muerte, causante, en sí, de la entropía universal. ¿Cuál es, en este panorama, la intención de lo humano en el mundo?

\section{La intención de lo humano}

La pregunta fundamental por el motivo que tiene lo humano para habitar en el mundo está abierta a interpretaciones diversas; sin embargo, lo captable fácilmente es que aquello que pueda motivar la existencia de lo humano en el mundo no es algo perpetuo. Tal como afirmó Schopenhauer: "Exigir la inmortalidad del individuo es querer perpetuar un error hasta el infinito". ${ }^{51}$ A pesar de ello, el filósofo alemán consideraba que la voluntad de vivir facultaba al individuo para mantenerse existiendo. Es evidente que Mainländer se deslindó, al menos en esto, de uno de sus autores predilectos.

\footnotetext{
${ }^{45}$ Mainländer, P., Filosofía de la redención, p. 138.

${ }^{46}$ Cioran, E., En las cimas de la desesperación, p. 49.

${ }^{47}$ Mainländer, P., Filosofía de la redención, p. 101.

${ }^{48}$ Cioran, E., En las cimas de la desesperación, p. 50.

${ }^{49}$ Mainländer, P., Filosofía de la redención, p. 104.

${ }^{50}$ Ibidem.

${ }^{51}$ Schopenhauer, A., El amor, las mujeres y la muerte, p. 108.
} 
Volpi reconoce que "Mainländer extrae la consecuencia opuesta a la de Schopenhauer: la cosa en sí no es identificada con la 'voluntad de vida' (...) sino más bien con la voluntad de muerte". ${ }^{52}$ Precisamente, la voluntad de muerte (Wille zum Tode) es extraída, según Mainländer, a manera de herencia derivada del suicidio de Dios. Puesto que Dios ha deseado dejar de ser, todo lo que fue favorecido a partir de su multipartición está impregnado de esta tendencia. La idea de muerte no está adoptada de una situación externa, desde fuera del individuo, sino que está depositada ineludiblemente en sí mismo, en lo que es. En ese tenor, Cioran admite que "la inmanencia de la muerte revela el triunfo definitivo de la nada sobre la vida, probando así que la muerte existe únicamente para actualizar progresivamente el camino hacia la nada". ${ }^{33}$ Cuando esta fatalidad implícita aflora, se traduce en conductas acordes que son ejecutadas por quien la padece. La congruencia con este sentir coadyuva al pensamiento visceral, el cual, más allá de ser despreciable, permite un tipo de seriedad y profundidad que no es posible sin la implicación emocional. De tal modo, el pensador visceral es capaz de una honestidad mayor, en la medida en que "las verdades provienen de un suplicio interior más que de una especulación gratuita". ${ }^{54}$

Lo que en la propuesta de Cioran equivale al pensamiento visceral, para Mainländer supone la categoría de lo inmanente, es decir, la esencia que condiciona el pensamiento del individuo. Tal esencialidad radicada en el pensador es la que lo orilla a la consideración del exterminio como intención de la vida. De tal modo, se infiere que la finalidad de existir, la más pura posible, es la de dejar de hacerlo. Naturalmente, nada puede desaparecer si no ha aparecido antes, ninguna entidad puede trasladarse al no-ser sin previamente haber sido. Desde esta óptica, la intención de lo humano es permitir que el ser sea por un espacio temporal limitado y posteriormente abdicar de la existencia y diluirse en la nada. Mainländer sugiere dejar de ser, permitir el no-ser, invitar a los vivientes a la consideración del exterminio, pues de cualquier manera la aniquilación final habrá de suceder sin que la importancia del consentimiento humano sea trascendente. El exterminio que Mainländer propone no es, por tanto, un deseo cobarde de exclusión del propio ser, sino una redención

\footnotetext{
${ }^{52}$ Volpi, F., El nibilismo, p. 48.

${ }^{53}$ Cioran, E., En las cimas de la desesperación, p. 50.

${ }^{54}$ Ibidem.
} 
requerida, necesaria, definida y establecida por lo absoluto de la Deidad primigenia de la que todo se ha derivado. La muerte a la vida es la redención y es ésa la intención de lo humano. Es por ello que "en el fondo, el filósofo inmanente ve en todo el universo tan sólo el más profundo anhelo por una aniquilación absoluta, como si estuviese oyendo el llamado claro que atraviesa todas las esferas celestiales: ¡Redención! ¡Redención! ¡Muerte a nuestra vida! Y la respuesta consoladora dice: Todos ustedes encontrarán el exterminio y serán redimidos". 55

Más aún, el exterminio no es opcional; la destrucción está depositada en el interior de todo lo existente. Cada acto, cada situación, cada pequeño detalle, insignificante o no, tiene su destrucción. Mainländer manifiesta que "el movimiento de la humanidad del ser al no ser, cubre por completo todos los movimientos particulares".56 El que cada desplazamiento, cambio y modificación conlleven esencialmente la aniquilación puede inducir a la conclusión de que "la humanidad completa está consagrada al exterminio". ${ }^{57}$ La aceptación del cierre final de todo lo existente no es compatible con la negación de la muerte o la pretensión de una consecutiva existencia en la que se perpetúa el ser. Por el contrario, "pensar que las cosas son el tiempo, que nacen y mueren, que salen de la nada y retornan a la nada, significa que ellas, a pesar de ser entes, han sido nada en el pasado y serán de nuevo nada en el futuro". 58

Es comprensible que un pensamiento de este tipo, sobre todo las conclusiones que arroja y las implicaciones que supone en la cosmovisión individual, genere una aversión inmediata, en consonancia con las derivaciones conclusivas que se gestan a través de las construcciones aprendidas. Es aquí, en el momento tenso de reconocerse sin sentido, donde se forjan las necesarias ficciones sobre un futuro de salvación, la continuidad del ser, el optimismo fantasioso o las cómicas explicaciones sobre la globalidad de la bondad humana como dadora de sentido. En la óptica de Mainländer, todas estas salidas son una ficción temeraria que elude la naturaleza implícita en todo lo viviente. El

\footnotetext{
${ }^{55}$ Mainländer, P., Filosofía de la redención, p. 73.

56 Ibidem, p. 74.

57 Ibidem.

58 Volpi, F., El nibilismo, p. 161.
} 
enfoque del pensador del Main, como modalidad transpersonal del abismo, no se sustenta en enfoques dadores de luz y plenitud o en concepciones de una Deidad que se mantiene viva y que redime por sí misma a lo humano, tal como puede encontrarse en las perspectivas de Eckhart o Erasmo. Aun considerando las obvias diferencias entre estos planteamientos, existe un punto en común: todo lo que ha sido derivado de una instancia transpersonal volverá a su fuente cuando la vida termine. Si la fuente ha sido un Dios que eligió suicidarse y del cual hemos sido emanación (como cree Mainländer), un Dios amoroso que nos espera tras la locura tempestuosa de la existencia (según concebía Erasmo) o una Deidad que nos cubrirá con su manto cuando logremos, aún en vida, separarnos de lo mundano de la existencia temporal (a la manera en que lo entendía Eckhart), lo cierto es que existe en tales especulaciones una intrínseca consideración de algo por encima de lo humano que aporta una explicación al hecho de que lo humano habite este mundo. La dimensión a la cual se llega tras el naufragio en el abismo de la vida es consistente en algo que es o en una nada. En el fondo, ambas posibilidades se fusionan tal como advierte Nietzsche: "Las características que son atribuidas al 'verdadero ser' de las cosas son precisamente los rasgos distintivos del no ser, de la nada". ${ }^{59}$

El reconocimiento de tal implicación última no es accesible si se vive distraído en una modalidad de existencia cuyos criterios están centrados en la trivialidad. En ese sentido, los bienes y deseos contemporáneos, tan centrados en el ser, en lo tangible, en lo visible, en lo posible y medible, son los que protegen y construyen una barrera ante la confrontación. Tal como siempre lo supo el filósofo de la redención, su pensamiento difícilmente podría considerarse apto para las mayorías. Él mismo, en un afán compensatorio, advirtió: "No puedo exigirle a un bruto -en materias filosóficas- que reconozca como su máximo bien el no ser. Para ello se requiere de una elevada formación y del más amplio horizonte espiritual, en caso de que el corazón no haya recibido, ya en la procreación, una orientación ascética". ${ }^{60}$

${ }^{59}$ Nietzsche, Friedrich, Cómo se filosofa a martillazos, Ciudad de México, Grupo Editorial Tomo, 2004, p. 37.

${ }^{60} \mathrm{Ibidem}$, p. 97. 


\section{Redención de la existencia}

Sin adentrarme ahora en la posibilidad de una continuación del ser aún más allá de lo actualmente tangible a nuestra capacidad sensitiva, lo cual merece un espacio aparte, sí puede reconocerse en Mainländer la apreciación de un valor absoluto que deviene en condicionamiento de todo lo inferior. Es decir, no se observa un rompimiento total con la lógica de la implicación piramidal. De tal modo, lo que aconteció con Dios, o el ser absoluto, deberá acontecer con todo lo que proviene de Él, a saber, la totalidad de lo existente. Efectivamente, "la filosofía mainländeriana se origina en un nuevo saber, que no reconoce estar fundamentado en una fe, pero que descansa en una confianza y elogio divino a la muerte". ${ }^{61}$ Ahora bien, si la muerte es, precisamente, la "redención de la existencia" 62 era oportuno, o al menos inevitable, haber existido para lograr dejar de existir.

En el paso que un individuo pensante debe transcurrir para forjar el requerido criterio que le permita gestar las conclusiones sobre su propio destino, siempre ha de encontrarse con conflictos y fricciones. No hay calma pacífica, "la vida del hombre es un perpetuo combate, no sólo contra males abstractos, la miseria o el hastío, sino contra los demás hombres. En todas partes se encuentra un adversario". ${ }^{63}$ La muerte, vista desde este parámetro, es una salida. No basta entonces, según se advierte, con un cambio parcial para superarse, sino que es ineludible un cambio sustancial, una modificación esencial que puede advenir sólo en función del cambio más definitivo: el paso de ser a dejar de ser. Mainländer coincide con Schopenhauer cuando éste concluye que: "Para conducir al hombre a un estado mejor, no bastaría ponerle en un mundo mejor, sino que sería preciso de toda necesidad transformarlo totalmente, hacer de modo que no sea lo que es y que llegara a ser lo que no es. Por tanto, necesariamente tiene que dejar de ser lo que es. Esta condición

${ }^{61}$ Baquedano, S., "El pesimismo entrópico en las cosmologías filosóficas de la voluntad", p. 20.

${ }^{62}$ Mainländer, P., Filosofia de la redención, p. 73.

${ }^{63}$ Schopenhauer, A., El amor, las mujeres y la muerte, p. 119. 
previa la realiza la muerte, y desde este punto de vista, se concibe su necesidad moral". ${ }^{64}$

De tal manera, el cambio radical es dejar de ser, pues "sólo el dejar de ser implicará la totalidad de la nada, volverse uno con la Nada". ${ }^{65}$ El suicidio de Dios ha provocado que la esencia de la aniquilación, de la anulación, de ser nada, esté implícito en la esencia del ser. La muerte no es entonces un paso advenedizo a un modo distinto de ser, sino la aniquilación total. Propiamente, "más allá del mundo, no hay ni un lugar de paz ni un lugar de tormento, sino sólo la nada". ${ }^{66}$ Siendo así, el tiempo del exterminio atrae consigo un estado de no movimiento y de no tiempo. Quien ingresa a la nada "no tiene calma ni movimiento, está en un estado ausente, como en el sueño, pero con la gran diferencia de que también lo que en el sueño es un estado ausente no existe más: la voluntad está aniquilada por completo". ${ }^{67}$ Muchas voces contrapuestas a tal aniquilación pueden surgir ante la afirmación de la imposibilidad de un más allá dotado de conciencia; igualmente, "podemos elaborar elegantes sugestiones (...) para la negación de la Nada, pero no escaparemos de ella por poner en nuestra mente que hemos escapado". 68

En esta tónica surge inevitable la pregunta: ¿Cuál ha sido la esencia divina que orilló a Dios a la consideración del suicidio? Mainländer se deslinda de la especulación sobre tal acertijo y afirma que "sobre la esencia de la divinidad precósmica jamás espíritu humano alguno podrá rendir cuenta". ${ }^{69}$ Indudablemente, podría conjeturarse una objeción consecuente: ¿Cómo afirmar la posibilidad del suicidio divino si no hay manera de "rendir cuenta" de las intenciones del Ser absoluto previo al Cosmos? Ante esta aparente aporía, Mainländer se sustenta en la revisión de paradigmas propuestos por pensadores que lo antecedieron en el problema que aborda. Coincide con Buda, por ejemplo, en que las situaciones que se viven en el presente han sido determinadas o elegidas durante un estado antecedente. Tras admitir que Buda

\footnotetext{
${ }^{64}$ Ibidem, p. 109.

65 Sevilla, Héctor, Contemplar la Nada, Ciudad de México, Ítaca, 2017, p. 309.

${ }^{66}$ Mainländer, P., Filosofía de la redención, p. 132.

${ }^{67}$ Ibidem.

${ }^{68}$ Sevilla, H., Contemplar la nada, pp. 309-310.

${ }^{69}$ Mainländer, P., Filosofía de la redención, p. 127.
} 
tenía razón, Mainländer refiere: “Todo lo que me afecta, todos los golpes y favores del azar son obra mía: yo los he querido. Pero no es recién en el mundo donde los acuso con fuerza omnipotente e incognoscible, sino antes del mundo, en la unidad simple, he determinado que ellos deben afectarme". ${ }^{70}$ Como puede observarse, uno de los argumentos centrales que Mainländer propone para el suicidio de Dios es que debió existir en un primer momento como un principio contenedor del cual todo fue derivado. La única manera en que el contenedor podía permitir la expansión de lo contenido era romperse a sí mismo, dejar de ser el contenedor. La elección de la que habla el filósofo del Main, aquella que todo individuo realiza antes de venir al mundo, no es una elección racional, en el entendido de que tal condición de elegir sería sólo posible tras una aculturación; lo que sí se advierte es que en el carácter de "contenido" (lo que hoy cada uno es) admitió un proyecto que devino en personal.

$\mathrm{Al}$ reconocer que el contenedor tuvo que vertirse a través del contenido, conformando con ello la entropía del universo, Mainländer concede un acierto al panteísmo. Coincide con tal postura en que "el destino del cosmos es uniforme, es movimiento de todo el mundo hacia una meta"; 71 a la vez, reconoce, y en esto se observa su separación del panteísmo, que "ninguna unidad simple en el mundo lleva a cabo el movimiento si actúa en individuosaparentes en una y otra dirección, sino que una unidad simple, antes del mundo, determinó todo el proceso, y en el mundo lo llevan a cabo sólo individuos reales". ${ }^{72}$ Los hombres, individuos reales, sustituyen su reconocimiento de tal sistema irrenunciable con la ilusión de su libertad. Cualquier acto contiene en su interior un conflicto entre la voluntad de vivir y de morir. El individuo puede estar distraído en su voluntad de vida y no corresponder a su esencial código interno que implica para sí la destrucción. El sustento del panteísmo, consistente en que todo es Dios, no es idéntico a la idea mainländeriana de que existe, más bien, un universo en el que todo, incluyéndolo, está derivado de una esencia divina que tiende a la aniquilación. De tal modo, los individuos

\footnotetext{
${ }^{70}$ Ibidem, p. 123.

71 Ibidem.

72 Ibidem.
} 
reales sólo lo son en medida que se convierten en contenedores (ya no en contenido) de la esencia sustancial del exterminio.

En los momentos en que exista cierta culpa por morir, o un temor desbordante por el posible juicio que de ello pudiese derivarse, Mainländer propone que el agonizante olvide todo lo que le provoque un sentimiento contrario a la redención, pues debe agudizar su vista y reconocer "que ha padecido lo suficiente en esta vida y que viviendo ya ha expiado todo"; 73 de tal modo, logrará morir en paz. Utilizar el criterio radical de Mainländer conduce a no eludir el compromiso hacia el exterminio, aun en los momentos previos a la muerte; en una perspectiva como la descrita, se considera que el moribundo "debería dirigirse a sus descendientes y exhortarlos, enfáticamente, a desistir de la vida, a la cual le es propio el sufrimiento". ${ }^{74}$

Asimismo, para Mainländer "tiene razón Platón", ${ }^{75}$ en el entendido de que "deja elegir a cada ser humano su propio destino antes de ingresar a la vida", 76 lo cual coincide con su idea de que los hombres contienen un plan esbozado previamente. No obstante, a diferencia del filósofo de la Academia, consideró que el hombre no elige su destino inmediatamente antes del nacimiento, sino, más bien, en forma previa a la existencia del mundo, es decir, "en el campo trascendente, cuando aún no existía el inmanente, ha determinado él mismo su destino". ${ }^{77}$

Por ello, "los panteístas tuvieron que equivocarse, pues atribuyeron el movimiento universal efectivamente existente a una unidad en el mundo"78 cuando, en realidad, tal unidad ya no existía más. Por otro lado, según Mainländer, la equivocación de Buda fue que, “de forma errónea, concluyó la total autosuficiencia del individuo en el mundo, a partir del sentimiento de total responsabilidad por todas sus acciones, que de hecho existen en él"; ${ }^{79}$ es decir, el mundo y el hombre ya contienen consecuencias inevitables que no son

${ }^{73}$ Ibidem, p. 106.

${ }^{74}$ Ibidem.

${ }^{75}$ Ibidem, p. 123.

${ }^{76}$ Ibidem.

${ }^{77}$ Ibidem.

${ }^{78}$ Ibidem, p. 137.

${ }^{79}$ Ibidem. 
producto de la libertad que antecede a una elección, sino de la vinculación inevitable que todo lo existente tuvo, en un principio, con el origen contenedor. En ese sentido, no se es libre de contener la semilla del exterminio, pero sí se posee cierta elección al no obstaculizarla o al permitir el entendimiento de que germinará tarde o temprano.

Finalmente, Mainländer se desprende del vínculo igualitario con Buda, Platón y los panteístas advirtiendo en forma sintética que:

\begin{abstract}
Nosotros, en cambio, situamos la unidad simple de los panteístas en un campo trascendente pasado y explicamos el movimiento universal uniforme como producto de la acción de esta unidad simple precósmica; nosotros unimos la semiautonomía del individuo y el poderío del azar en el mundo que es totalmente independiente de él-, en el campo trascendente, en la resolución uniforme de Dios de convertirse al no ser, y en la elección uniforme de los medios para efectuar la resolución. Finalmente, no unimos libertad y necesidad en el mundo, donde no hay lugar para la libertad, sino en medio del abismo que separó el campo trascendente -recuperado del ocaso a través de nuestra razón- del campo inmanente..$^{80}$
\end{abstract}

Mainländer se separa así de los planteamientos que lo llevaron en un principio a elaborar sus conclusiones. Por tanto, el suicidio de Dios coincide con un mundo en el que todo está permitido, un mundo saturado de individuos que, creyéndose sin ley, al promover y forzar la destrucción del mundo y de los otros, sólo evidencian su contenido esencial de aniquilación, el cual provoca una reacción destructiva que no deriva del ejercicio de la libertad. Para ser virtuosa, la aniquilación tendría que haber sido elegida por el que es aniquilado; por el contrario, elegir por otro, aniquilarle contra su voluntad, si bien obliga su paso al no-ser, no procede de una auténtica voluntad de muerte.

De tal modo, se resuelve en parte lo que Camus planteó más de medio siglo después de la muerte de Mainländer: "O no somos libres y el responsable del mal es Dios todopoderoso, o somos libres y responsables, pero Dios no es

${ }^{80}$ Ibidem. 
todopoderoso". ${ }^{81}$ En la lógica del filósofo de la redención, el que la libertad humana sea inoperante no implica la responsabilidad directa de Dios, puesto que su único acto libre fue el suicidio del cual se derivó la implicación de todo lo que, después de Él, logró ser. Asimismo, no hay posibilidad de ser libres ni absoluta responsabilidad humana, pero no por ello se implica que Dios no sea todopoderoso; Dios fue libre cuando eligió divinamente su propia redención del plano del Ser. Como se observa, Mainländer no procede en forma beligerante ante la categoría de lo absoluto en la divinidad. Al contrario, la necesidad de la redención procede de la implicación que tiene la totalidad de lo existente con lo absoluto precósmico.

Por otro lado, queda abierta la posibilidad de que la redención del hombre sea en función de salvarlo de un mundo sin Dios, por lo que, es fácil advertir, la mejor manera de regresar a Él sería hacerse uno en la Nada que ahora constituye. En este plano coinciden las brillantes palabras de Cioran cuando cuestiona en el Breviario de los vencidos: "¿No sientes que cuando te sumerges implacablemente en la nada, la nada es, que respira, tiembla y se arremolina?". 82

Mainländer, un filósofo visceral desde la óptica de visceralidad de Cioran, o un filósofo de la inmanencia, por derivación atribuible a sus textos, tuvo en su desenlace el punto final de sus argumentaciones. Por su parte, Cioran no eligió un cierre similar y se alejó de la opción del suicidio. La conclusión del nacido en Rumania fue la siguiente: "A pesar de que la vida me resulta un suplicio, no puedo renunciar a ella, dado que no creo en lo absoluto de los valores por los que debería sacrificarme". ${ }^{83}$ Contrariamente, Mainländer logró el mérito promisorio de hablar a través de su aniquilación, al elegir concederse el triunfo elocuente de ser un pensador "cuya muerte fue conclusión de una argumentación ontológica". ${ }^{84} \mathrm{El} 1$ de abril de 1876, apenas tuvo en sus manos la primera edición de La filosofía de la redención, Mainländer subió a un alto escalón elaborado con varios ejemplares de su propia obra y se

${ }^{81}$ Camus, A., El mito de Sísifo, p. 75.

82 Cioran, E., Breviario de los vencidos, p. 117.

${ }^{83}$ Cioran, E., En las cimas de la desesperación, p. 63.

84 Baquedano, S., "El pesimismo entrópico en las cosmologías filosóficas de la voluntad", p. 10. 
ahorcó. Ahí cumplió uno de los deseos manifestados en un poema que escribió en 1859: "A la muerte quiero ir como el viento tormentoso que de norte a sur sopla salvaje. Como los tajantes relámpagos, así quiero acabarme". ${ }^{85}$

En forma radical debe admitirse que "quien no le teme a la muerte, es el único que puede hacer algo por los demás", 86 aunque esto sea, procedentemente, una invitación al exterminio. Mainländer nos enseña, más allá de la presencia o elocuencia de sus pensamientos, cuestión que puede ser discutida, el sentido y honorabilidad de la congruencia, virtud que, debido al miope afán humano contemporáneo de promover la autosuficiencia y la autoliberación, desgraciadamente ha sido aniquilada casi por completo.

\section{Variantes de la redención}

Como es de esperar, se puede coincidir con algunos planteamientos realizados por Mainländer sin que se esté obligado al suicidio por ello. Si bien, según Camus, "el hombre se ha limitado a inventar a Dios para no matarse" 87 y podría decirse que "así se resume la historia universal hasta este momento",, 8 también ha de admitirse que es posible inventar, sin importar si esto es honesto, la existencia de un Dios suicida para matarse. Creer en un Dios que se suicida con tal de que su suicidio sea el punto de partida (y llegada) de todo lo humano es también un aparente sostén transpersonal de la decisión, pero no coincide con la vivencia de la angustia plena de saberse sin certezas. Esto se comprende al asimilar que "los hombres usamos la razón, pero los productos de la razón no son la razón sino sólo suposiciones". ${ }^{89}$

Evidentemente, la idea de un Dios suicida es una suposición. Es cierto que podría ser absurdo considerar a un Dios que se suicida, tal como lo puede resultar un Dios salvífico. ¿De qué tendría que ser salvada o redimida la humanidad sino precisamente de ambas ideas de Dios? Aun en lo absurdo

\footnotetext{
${ }^{85}$ Mainländer, P., Diario de un poeta, p. 81.

${ }^{86}$ Mainländer, P., Filosofía de la redención, p. 129.

${ }^{87}$ Camus, A., El mito de Sísifo, p. 140.

88 Ibidem.

${ }^{89}$ Sevilla, H., Contemplar la nada, p. 188.
} 
existe la posibilidad de afrontar las implicaciones derivadas, sin importar el costo. En ese sentido, "lo absurdo es reconocimiento aceptado, el hombre se resigna a él y a partir de ese instante sabemos que ya no es lo absurdo. Dentro de los límites de la condición humana, ¿qué mayor esperanza que la que permite escapar a esa condición?"90

En otros autores también existe la conciencia de la necesidad de morir para trascender la vida mundana y lograr perpetuarse en un principio transpersonal. En algunos textos de Teresa de Jesús, por ejemplo, está claro que su intención era morir; en su poema Vivo sin vivir en mi solicita: "venga ya la dulce muerte, el morir venga ligero, que muero porque no muero". ${ }^{91}$ Detrás de su anhelo palpitaba el deseo de encontrarse con Dios, ganar la vida eterna. En Mainländer existe una similar intención de dejarse guiar, precisamente, por el designio inicial de Dios, según él lo concebía. En tal comparación, la intención no es validar al filósofo del Main, sino ejemplificar diversamente lo que Erasmo sentenció en su Elogio de la locura: "Ha sido siempre costumbre de los sabios confiar al papel sus alegrías y tristezas, como amigo fiel en cuyo pecho se puede vaciar toda la turbulencia del corazón”. ${ }^{92}$

Russell, el genial filósofo inglés, escribió lo siguiente a su amada Constance Malleson en una carta elaborada en 1916: "En lo más íntimo de mí mismo hay siempre y eternamente un terrible dolor, un curioso dolor salvaje, una búsqueda de algo más allá de lo que el mundo contiene, de algo transfigurado e infinito, la visión beatífica de Dios no la encuentro, no creo que pueda encontrarse; pero el amor a ello es mi vida, es como un apasionado amor por un fantasma". ${ }^{93}$ Tales líneas nos conducen a reconocer la presencia latente de una inspiración russelliana que estuvo centrada en el anhelo de un algo transpersonal que, columpiándose en las postrimerías de la ilusión y la conciencia, mantenía los esfuerzos del eximio pensador.

${ }^{90}$ Camus, A., El mito de Sisifo, p. 145.

${ }^{91}$ Recomiendo consultar sobre este pasaje: Sáenz, Hilario, "Notas a la glosa Vivo sin vivir en mí de Santa Teresa y de San Juan de la Cruz", Modern Language Quaterly, 13, 1952, pp. 405-408.

${ }_{92}$ Erasmo de Rotterdam, Elogio de la locura, Ciudad de México, Grupo Editorial Éxodo, 2007, p. 182.

${ }^{93}$ Scharfstein, B., Los filósofos y sus vidas, p. 329. 
En unos de sus textos, Cioran afirma que "la ilusión de estar aquí es más estimulante que la serenidad de no estar en ninguna parte, de estar en los cielos". ${ }^{94}$ De hecho, la preferencia por la vida, a pesar de sus penumbras, fue el aliciente que mantuvo la vida de Cioran, permitiéndole así engrosar su amplio repertorio de obras. Para él, la redención no podría encontrarse en las creencias religiosas, pues la intención es no dejarse persuadir por ellas, de modo que se pueda obtener mayor libertad en la expresión propia. Reconoció que "dos atributos tiene el hombre: la soledad y el orgullo. Él vive sobre la tierra para sacarlos a la luz. Pero entonces aparece la religión: un sistema de remedios que socavan la existencia". ${ }^{95}$ Cioran desistió de la opción del suicidio, lo cual fue una variante de la redención que propuso Mainländer, pues incluso cuando en éste la intención era liberarse de algún modo, existía una dependencia directa a los valores emanados de su propia concepción de la decisión divina.

Cioran terminó por asentar que "no existe una voluntad o una decisión racional de suicidarse, sino únicamente causas viscerales e íntimas que nos predestinan a ello". 96 De tal modo, "no sólo la vida no tiene ningún sentido, sino que no puede tenerlo", 97 aunque tal sentido se intente que sea, precisamente, terminar con ella, en conjunción y aplicación solemne de algún supuesto plan de Dios, cualquiera que éste sea, para la vida o la muerte.

La obra de Mainländer estuvo centrada en resolver el enigma del mundo, ése que se origina cuando es comprendida la

difícil y ambivalente relación que el hombre mantiene con las potencias de la naturaleza: frente a ellas, se siente, por un lado, completamente dependiente, como una nada, que tiembla ante un poder implacable, independiente de él, al que diviniza; por otro, cuando el peligro ha pasado y se siente a salvo, el individuo vuelve a sentir la fuerza rebelde de su tozudo $y 0 .{ }^{98}$

\footnotetext{
${ }^{94}$ Cioran, E., Breviario de los vencidos, p. 32.

${ }^{95}$ Ibidem, p. 28.

${ }^{96}$ Cioran, E., En las cimas de la desesperación, p. 95.

${ }^{97}$ Ibidem, p. 180.

${ }^{98}$ Pérez Cornejo, M., "Introducción” a Mainländer, P., Filosofía de la redención, p. 11.
} 
El enigma del mundo provee los ingredientes para sumergirse en el abismo, uno del cual es posible resurgir mediante un enfoque transpersonal que conduzca a una salida emergente a través de la elección por la vida o la muerte.

La filosofía de lo transpersonal implícita en Mainländer le permitió comprender que las respuestas sobre el misterio de la vida no se circunscriben a los deseos personales, ni están sustentadas en pletóricos caminos de luz, sino en el abismo de la incertidumbre, de la pérdida y de la caída. Fue capaz de conectar con la mística y por ello estuvo interesado en conocer distintos ámbitos de la espiritualidad. En otras circunstancias probablemente hubiese dedicado su vida a las cuestiones sagradas. Él mismo llegó a indicar durante un viaje por Roma a los veintidós años: "Sé con certeza que, si viviésemos en la Edad Media, yo sería un monje cartujo". ${ }^{99}$ Por ello, en su labor como escritor no estaba preocupado por la recepción comercial de sus ideas, sino que lo motivó una inspiración superior; en ese sentido, "Mainländer no escribe para nadie, escribe para la Humanidad'. 100

\section{Conclusión: La filosofía como redención}

La filosofía puede ser redentora, en cierto modo, de la necesidad de encontrar una respuesta que redima. Esa es la paradoja. Asimismo, "uno no debería de pensar en lo paradójico a la ligera, pues la paradoja es la fuente de la pasión del pensador, y el pensador sin paradoja es como un amante sin sentimiento: una mediocridad insignificante. Pero el punto supremo de toda pasión es siempre querer su propio ocaso". ${ }^{101}$ Una filosofía salvífica sería finalmente la que otorga la erradicación de la necesidad de ser salvado. Una pregunta respondida no es la que asesina la interrogante, sino la que permite comprender que la respuesta nunca logra ser absoluta o, mejor aún, que no importa en lo absoluto.

\footnotetext{
${ }^{99}$ Pérez Cornejo, M., "Dolor sereno: las poesías de Philipp Mainländer en su contexto biográfico y filosófico”, Mainländer, P., Diario de un poeta, p. 22.

100 González Serrano, Carlos J., "La odisea del espíritu mainländeriano: en busca del sí mismo", Mainländer, P., Diario de un poeta, p. 28.

101 Scharfstein, B., Los filósofos y sus vidas, p. 392.
} 
Si aceptamos que "gran parte de la filosofía se crea en respuesta a la depresión, que el filósofo trata de trascender mediante un interés apasionado, que emplea el desamparo y el desamor como estímulo para la creación intelectual $y$, por tanto, para el placer", ${ }^{102}$ concederemos también que la filosofía puede regirse y alinearse por la motivación personal más íntima. Para Mainländer no hay motivos para eludir la noche de la aniquilación, la entrada a la nada; tal como todo filósofo, busca convencer que sus razones son aceptables y oportunas: "Quisiera, en adelante, destruir además todos los motivos fútiles que puedan amedrentar a los hombres que buscan la noche sosegada de la muerte. Y si mi confesión (...) puede tener el vigor para apoyar a cualquiera de mis prójimos en su lucha contra la vida, entonces, la efectúo en este acto". ${ }^{103}$

En concordancia con Mainländer, debe admitirse junto a Volpi que "[1]a filosofía no puede eximirse de pensar la nada, si es verdad que para cumplir con el deber que le es propio, vale decir, la pregunta acerca del ser en cuanto ser, debe deslindar a este último de su oposición esencial, es decir, de la nada". ${ }^{104}$ La reflexión sobre la nada devino en Mainländer el anhelo de ella; por ello, recomendó el suicidio como una vía de negación radical de la voluntad. En esto observó la alternativa de lograr una redención de la existencia para conseguir, tal como afirmaba que lo hacían los sabios, "mirar a los ojos, fija y alegremente, a la nada absoluta". ${ }^{105} \mathrm{Si}$ bien es cierto que "el conocimiento a pequeñas dosis cautiva y a fuertes dosis decepciona", 106 las experiencias íntimas fundamentales derivadas del conocimiento adquirido no sólo deben entenderse, sino también "hacerse vida", aunque eso suponga, precisamente, la muerte.

Mainländer no pretendió morir por nadie más ni utilizó su vida como un camino a la Verdad, sino que eligió por su cuenta lo que creyó que era su destino, no como imitación de Dios, sino como congruencia con la derivación implícita del suicidio de la Fuente original. La elección por la muerte sólo puede

\footnotetext{
102 Ibidem, p. 124.

103 Mainländer, P., Filosofía de la redención, p. 130.

104 Volpi, F., El nibilismo, p. 18.

105 Mainländer, P., Filosofía de la redención, p. 138.

${ }^{106}$ Cioran, E., En las cimas de la desesperación, p. 206.
} 
hacerla quien va a morir, nunca en función de otro ni por motivos distintos a la redención. Según como lo concebía el autor de Die Philosophie der Erlösung, su obra es continuación de las de Kant y Schopenhauer, además de ser "confirmación del budismo y el cristianismo puro". ${ }^{107}$ Contrariamente, en alusión a que Jesús no eligió suicidarse, Cioran refiere que "quien pretendió morir por nosotros no murió, lo mataron". 108 Ante tales conjeturas, es claro que lo que se conciba de Dios condicionará la vida; en otras palabras, la visión sobre lo absoluto representa una fuente intensa de motivos para actuar de uno o de otro modo. Cabe entonces la pregunta nietzscheana: “ ¿Es el hombre tan sólo un error de Dios? ¿ O es Dios tan sólo un error del hombre?”. ${ }^{109}$ Es en tal óptica por la que se vuelve fundamental una filosofía de lo transpersonal que supere la automatización de las respuestas y evite que la reflexión sea asfixiada en función de una creencia enraizada en punzantes infantilismos.

¿Cuál es entonces la obligada tarea? ¿Concebir el suicidio de Dios o matar la idea de Él? También cabe, como en el caso de Mainländer, asumir las consecuencias de seguir el ejemplo de la divinidad, aun cuando el testimonio inicial sea incierto. Si Dios se ha suicidado es porque existió en un momento antecedente, pero su muerte lo expandió a todo lo que existe. La creencia en el suicidio de Dios, al igual que cada una de las generadas a partir de la suposición de su omnipotencia, dirige al creyente a asumir las consecuencias últimas de su osadía. A un Dios que se suicida no podría esperarle el paraíso, sino el universo, un espacio finito en donde las ficciones del humano comienzan y prosiguen hasta encontrar su fin mediante el oportuno encuentro con una muerte que nos salva definitivamente de la vida.

El sentido que de esto podría derivarse consiste en reconocer el consecuente interior vivo y palpitante que, conectado a realidades superiores a las conocidas, es capaz de aletear en torno a nuestra insuficiente comprensión. En los años de su juventud, Mainländer plasmó en su poema Junto a la tumba de Virgilio lo que podría ser una especie de confesión ampliamente reveladora de su atención a lo transpersonal: "A menudo, al caer el rocío de las perfumadas hojas de las flores, me parece oír una voz que murmura quedamente: confía en

\footnotetext{
${ }^{107}$ Mainländer, P., Filosofía de la redención, p. 46.

${ }^{108}$ Ibidem, p. 107.

${ }^{109}$ Nietzsche, F., Cómo se filosofa a martillazos, p. 12.
} 
las palabras que te dicte tu interior palpitante. $\mathrm{Y}$ aunque no la conozco siento otra vida, totalmente diferente a este inquieto y preocupado esfuerzo, lleno de dolor y furiosa prisa". ${ }^{110}$

Podría parecer que la experiencia del filósofo alemán es ajena a la de los ciudadanos del siglo XXI. No obstante, "el nihilismo no es tanto el oscuro experimento de extravagantes vanguardias intelectuales, sino que forma parte ya del aire mismo que respiramos". ${ }^{111}$ Corresponde, entonces, rescatar los conceptos y la intensidad implícita en la redención comprendida por Mainländer, de modo que nos corresponda, en lo íntimo y personal, elegir una opción verdaderamente propia.

La filosofía es una redención por un momento limitado, pero al menos habrá cumplido su cometido si logramos comprender, a través del viento temporal que somos, que no es la muerte la que termina con la vida, sino que es la vida la que nos propicia la muerte, pues sin importar la modalidad de la existencia, la formalidad de la convención o el lenguaje de las ideas sobre la Deidad, su suicidio o redención, "vivir nos mata a todos". ${ }^{112}$

Recibido: 07/2018; aceptado: 04/2019

${ }^{110}$ Mainländer, P., Diario de un poeta, pp. 91-93.

111 Volpi, F., El nibilismo, p. 16.

112 Sevilla, H., Contemplar la nada, p. 378. 